\title{
Bioactivity of oats as it relates to cardiovascular disease
}

\author{
Danielle Ryan, Megan Kendall and Kevin Robards* \\ School of Wine and Food Sciences, Charles Sturt University, Locked Bag 588, Wagga Wagga, New South Wales, Australia 2678
}

\begin{abstract}
The food consumption of oats has increased in recent years due to a perceived association with a range of health benefits. Oats are unusual in that the bran is not as physically distinct as in other cereals. This provides a possible benefit in providing a high $\beta$-glucan content of the grains. However, oats contain many other phytochemicals including a range of antioxidants that may be associated with health benefits, although the evidence for such benefits is largely indirect and often confusing and contradictory. Nevertheless, the consumption of oats as part of a balanced diet does seem a reasonable approach.
\end{abstract}

Antioxidants: Avenanthramides: Lignans: Phytochemicals

\section{Introduction}

Oats (Avena sativa) have historically been a multipurpose crop cultivated in temperate regions for numerous uses (for example, hay, pasture, silage) other than for cash grain. Oats production until relatively recently had been in a long-term decline as other cereals have provided better returns to farmers and the traditional use as feed for working horses has diminished. Nevertheless, total world production in 2005 was 24.6 million $\mathrm{Mt}^{1}$ although only a very small proportion was for human food use and approximately 3 million Mt of the oat crop entered world commerce. Oats were less favoured for food use than other grains because of a bland taste and a tendency to spoilage. Despite these issues, oats became a staple in Germany, Ireland, Scotland and the Scandinavian countries. Gibson $\&$ Benson $^{2}$ note that oats were defined in Samuel Johnson's dictionary as 'eaten by people in Scotland, but fit only for horses in England. A Scotsman's retort to this is, That's why England has such good horses, and Scotland has such fine men!'. This remark contained considerable insight into the merits of oats as their worldwide food consumption increased dramatically in the $1980 \mathrm{~s}$ as a result of the growing recognition of their nutritional value. It is notable that oats were used for medicinal purposes before being used as a food ${ }^{3,4}$, although the distinction between medicinal and food use of commodities is relatively recent ${ }^{5}$.

Dehulled oats or groats are now used in a variety of food products. The outer layers of the groat comprise the bran which is not as structurally distinct as, for example, the bran of wheat. Thus, the dehulling process does not remove the bran and germ, allowing the groat to retain a concentrated source of fibre and nutrients. Oats have a high $\beta$-glucan content which is of advantage in human nutrition, as it is considered to be anti-atherogenic ${ }^{6,7}$, to enhance immune response to infection ${ }^{8,9}$, to decrease peak insulin and glucose concentrations ${ }^{10,11}$ and to be responsible for lowering serum and plasma cholesterol levels ${ }^{12,13}$. Oats may also provide a useful substitute for wheat products in patients suffering from coeliac disease ${ }^{14}$.

The present paper examines the supposed health benefits of oats with reference to its phytochemical complement and, in particular, that of antioxidant compounds including the avenanthramides ${ }^{15}$. The salient features of relevant analytical methods are provided where appropriate to an understanding of bioactivity.

\section{Health benefits of oats}

Compared with other cereals, oats are characterised by a lower carbohydrate content ${ }^{16}$, with higher protein and lipid contents. However, in common with other grains, starch remains the most abundant component where it constitutes about $60 \%$ of the DM of the entire oat grain. The lipid content, which ranges from 4 to $16 \%$ in the groat ${ }^{17}$, is the highest among all the common cereal grains ${ }^{18}$, thus accounting for the greater tendency of oats to spoilage. This high lipid content is also undesirable from the human nutritional viewpoint and lower lipid-content grains are generally favoured for food use, other factors being equal. However, oats are rich in both mono- and di-unsaturated fatty acids ${ }^{17}$ and, compared with other cereals, oats typically contain more oleic and less linoleic acid. This lipid composition is desirable but research on nutritional aspects of oats has generally not targeted the lipid profile. On the

\footnotetext{
Abbreviations: DPPH, 2,2-diphenyl-1-picrylhydrazyl; Trolox, 6-hydroxy-2,5,7,8-tetramethylchromane-2-carboxylic acid.

*Corresponding author: Professor Kevin Robards, fax + 612 69332866, email krobards@csu.edu.au
} 


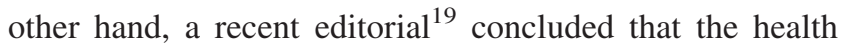
benefits of whole grains are associated with the bran or dietary fibre. Cereals contribute quantitatively the most important part of dietary fibre. Milling of cereal grains generally removes the bran and germ layers that are rich in fibre and phytochemicals, causing significant nutrient losses. Oats are exceptional in that they are usually consumed as the whole grain.

The first human trials on the effects of oat consumption on plasma cholesterol were reported in $1963^{20}$ and subsequent studies up to 1994 have been summarised ${ }^{20}$. In contrast to studies with wheat, most of the early studies plus more recent ones ${ }^{21-31}$ (Table 1) have reported a significant reduction in total and LDL-cholesterol following the consumption of oats either as rolled oats or as oat bran. Wheat bran is now considered to be inert in terms of CVD and has been used in many studies as the placebo control. The presence of the phyto-oestrogen enterolactone in wheat gives a plausible explanation as to the beneficial effects infrequently observed when wheat is utilised as a placebo ${ }^{29}$. The evidence supporting the benefits of oats consumption was sufficient to induce the United States Food and Drug Administration to approve a health claim on food products relating to the consumption of whole oats ${ }^{32}$.

Nevertheless, studies of oat consumption have demonstrated positive as well as no effects on CVD risk factors such as cholesterol concentration ${ }^{33}$. A meta-analysis, in which twenty trials were included, found a modest reduction of $0.13 \mathrm{mmol} / \mathrm{l}$ in total cholesterol concentration following daily intake of soluble fibre from oat products for $18 \mathrm{~d}$ to 3 months ${ }^{34}$. Lovegrove et al. ${ }^{23}$ found no changes in fasting plasma concentrations of total cholesterol, LDL-cholesterol and TAG but a decline in HDL-cholesterol following the consumption of oat bran concentrate equivalent to a daily intake of $3 \mathrm{~g} \beta$-glucan for 8 weeks. In another study, plasma HDL-cholesterol concentration increased after a daily intake of oat bran for 6 weeks ${ }^{35}$. However, many other studies have reported a lowering of total and/or LDLcholesterol concentrations following the consumption of fibre from oat products $21,22,24,36-38$. The lowering effect was time dependent, related to apo-E phenotype $\mathrm{e}^{33,37}$ and other dietary components and most pronounced in hypocholesterolaemic men and women.

With the undertaking of the National Cholesterol Education Program Step 1 diet, total cholesterol, LDLcholesterol, TAG levels, intakes of total and saturated fats, dietary cholesterol and BMI were all reduced within the allfemale (postmenopausal) experimental group after 3 weeks $^{25}$. The additional intervention of an oat-soya or oat-milk protocol in conjunction with the Step 1 diet for a further 6-week period showed a continued significant reduction in total cholesterol and LDL-cholesterol that was

Table 1. Summary of representative studies involving consumption of $\beta$-glucan from oats

\begin{tabular}{|c|c|c|c|}
\hline Subjects & Oat product & Outcome & Reference \\
\hline Healthy adults ( $n$ 62) & Fermented oat products & $\begin{array}{l}\text { Significant reduction in total } \\
\text { cholesterol }\end{array}$ & Martensson et al. $(2005)^{21}$ \\
\hline $\begin{array}{l}\text { Male adults } \\
\text { (moderate hypercholestero- } \\
\text { laemia) ( } n 52)\end{array}$ & Oat milk & $\begin{array}{l}\text { Significant reduction in total and } \\
\text { LDL-cholesterol }\end{array}$ & Onning et al. $(1999)^{22}$ \\
\hline Healthy adults ( $n$ 62) & Oat bran concentrate & $\begin{array}{l}\text { No significant difference in total or } \\
\text { LDL-cholesterol, glucose and } \\
\text { insulin between test and pla- } \\
\text { cebo (wheat product) }\end{array}$ & Lovegrove et al. $(2000)^{23}$ \\
\hline $\begin{array}{l}\text { Adults } \\
\text { (hypercholesterolaemic) } \\
\text { (n 112) }\end{array}$ & $\begin{array}{l}\text { National Cholesterol Education } \\
\text { Program Step } 1 \text { diet plus } \\
\text { snack bar, cereal and beverage } \\
\text { (containing phytosterols and } \\
\beta \text {-glucan) }\end{array}$ & $\begin{array}{l}\text { Significant reduction in total and } \\
\text { LDL-cholesterol }\end{array}$ & Maki et al. $(2003)^{24}$ \\
\hline Female adults ( $n$ 127) & $\begin{array}{l}\text { National Cholesterol Education } \\
\text { Program Step } 1 \text { diet plus oats } \\
\text { and milk, or oats and soya, or } \\
\text { wheat and milk, or wheat and } \\
\text { soya (cooked oatmeal or oat } \\
\text { bran cereal) }\end{array}$ & $\begin{array}{l}\text { Significant reduction in total and } \\
\text { LDL-cholesterol for oats-soya } \\
\text { and oats-milk groups only }\end{array}$ & Van Horn et al. $(2001)^{25}$ \\
\hline Healthy adults ( $n$ 152) & Ready-to-eat oat cereal & $\begin{array}{l}\text { Significant reduction in total and } \\
\text { LDL-cholesterol }\end{array}$ & Karmally et al. (2005) 26 \\
\hline $\begin{array}{l}\text { Male overweight subjects } \\
\text { (hypercholesterolaemic) } \\
\text { (n 235) }\end{array}$ & $\begin{array}{l}\text { Oat bran (incorporated in bread, } \\
\text { sauces and desserts) }\end{array}$ & $\begin{array}{l}\text { Significant reduction in total and } \\
\text { LDL-cholesterol, apo B }\end{array}$ & Berg et al. $(2003)^{27}$ \\
\hline Healthy adults $(n 30)$ & $\begin{array}{l}\text { Oatmeal and oat-bran ready-to- } \\
\text { eat cereal }\end{array}$ & $\begin{array}{l}\text { No significant change in flow- } \\
\text { mediated vasodilation after } \\
\text { acute or sustained ingestion }\end{array}$ & Katz et al. $(2001)^{28}$ \\
\hline Healthy adults $(n 50)$ & Rolled oats & $\begin{array}{l}\text { Oat ingestion prevented endo- } \\
\text { thelial dysfunction induced by } \\
\text { acute fat ingestion }\end{array}$ & Katz et al. $(2001)^{29}$ \\
\hline Healthy adults (typically $n 10$ ) & Oat gum & $\begin{array}{l}79-96 \% \text { of change in plasma } \\
\text { glucose and insulin attributable } \\
\text { to viscosity }\end{array}$ & Wood et al. $(1994)^{30}$ \\
\hline $\begin{array}{l}\text { Adults with elevated serum } \\
\text { total cholesterol }(n 36)\end{array}$ & Oat bran & $\begin{array}{l}\text { Serum total cholesterol declined } \\
\text { transiently }\end{array}$ & Uusitupa et al. $(1997)^{31}$ \\
\hline
\end{tabular}


not found in those following a wheat-soya or wheat-dairy protocol. Significant trends discovered in analysis of the $3 \mathrm{~d}$ food records (taken between week 3 and week 9) included an increase in soluble fibre intake in the oat groups, with a decrease in soluble fibre in the wheat groups; an increased intake of both dietary $\mathrm{Fe}$ (haeme $v$. non-haeme $\mathrm{Fe}$ not specified) and vegetable protein was also found in the oat groups. Dietary adherence was monitored by blood markers, food records and a matched-intervention log.

The National Cholesterol Education Program diet has been utilised in other studies of participants undergoing lifestyle change ${ }^{26,27}$. After an initial 5 weeks adhering to the Step 1 diet and lifestyle modifications, subjects were placed into one of two experimental groups: group 1 being assigned to an oat cereal with $3 \mathrm{~g} \beta$-glucan/d, and group 2 assigned to a maize cereal without soluble fibre; each intervention lasted 6 weeks. There was no difference between the groups for total energy intake, percentage energy as fat or saturated fat, or cholesterol intake. Additionally, there were no baseline differences in soluble fibre intake. With the addition of an oat-based meal containing $3 \mathrm{~g} \beta$-glucan/d, significant reductions in total cholesterol and LDLcholesterol were observed; these reductions were not seen in the maize group. It was not indicated whether the commercially available oat cereal used in the study was fortified with folate, so confounding may have occurred as increased folate intake appears to lower homocysteine levels, a potential factor for vascular diseases. In the case of the Step $2 \operatorname{diet}^{27}$, an oat-enriched diet comprising 35-50 g oat bran/d had an enhanced effect on lowering total and LDL-cholesterol.

While high plasma total cholesterol and LDL-cholesterol are viewed as classic risk factors for CVD, endothelial dysfunction has not been proven to anticipate coronary disease. However, endothelial dysfunction does correlate strongly with risk factors for CHD such as obesity, diabetes, impaired glucose tolerance and insulin resistance, which are known classic risk factors for CVD and CHD. Therefore, endothelial dysfunction is increasingly becoming viewed as an indicator of both micro- and macrovascular risk. A study involving the consumption of oats-only, oats and vitamin $\mathrm{E}$, or a placebo protocol revealed that in overweight, dyslipidaemic adults neither the oats, the oats and vitamin, nor placebo protocol increased flow-mediated vasodilation significantly after either acute testing or after sustained consumption of 6 weeks in response to a high-predominantly saturated-fat provocation meal ${ }^{39}$. However, the oatonly treatment did show a non-significant increase in flow-mediated vasodilation, although the results of this study may be misleading in that the high-fat provocation meal, which generally increases endothelial dysfunction in susceptible adults, did not induce acute endothelial dysfunction beyond that already presented by the participants at baseline. This and other studies by the same group $^{28,29,39}$ suggest that whole oats and vitamin E opposed the endothelial dysfunction induced by acute fat ingestion while wheat cereal, containing predominantly insoluble fibre, exerted no apparent effect.

As determination of habitual food intake was not employed in any of these studies ${ }^{28,29,39}$, typical daily intakes of nutrients were not assessed. Factors such as habitual dietary fibre intake, in particular the amounts of soluble as compared with insoluble fibre consumed, could exert a level of confounding for which there was no accounting. Additionally, with study methods requiring the ingestion of a wheat- or oat-based breakfast cereal each day for a prolonged length of time, displacement of other breakfast foods could have occurred influencing 'normal' endothelial function. For example, with the displacement of high-fat foods such as bacon by an oat-based cereal, we would assume a reduction in endothelial dysfunction would occur due to limiting saturated fat intake. These factors could further influence glycaemic control, and energy intake and nutrient intake, which could confound results.

The importance of dietary fibre has been ascribed mainly to the water-soluble mixed linkage $(1,3)(1,4)-\beta$-D-glucans ${ }^{40}$ which are the predominant polysaccharide constituents of endosperm cell walls constituting approximately $85 \%$ of the wall in oats ${ }^{41}$. The $\beta$-glucan content of oats varies widely $^{42,43}$ as shown in a trial involving five oat varieties in four variety trials during a 2 -year period where $\beta$-glucan content varied from 1.9 to $5.1 \%$ in the groats ${ }^{44}$. Doseresponse data remain inconclusive ${ }^{20}$ although the fibre composition of the oats is often not reported. Moreover, dietary fibre comprises four components: NSP (soluble fibre including pectins, gums and mucilage but mainly $\beta$-glucans; and insoluble fibre including cellulose and hemicelluloses); lignin; resistant starch; non-digestible oligosaccharides (raffinose, stachyose, oligofructose and inulin). Many analytical methods are available for measuring dietary fibre and some of these measure NSP only whilst others measure all of the above components. This has implications when reviewing evidence regarding the health benefits of different types of dietary fibre and particularly doseresponse curves.

The physiological effects of $\beta$-glucans have been ascribed to several mechanisms ${ }^{32}$. One proposed mechanism involves an increased viscosity of intestinal chyme due to their gel-forming properties ${ }^{30}$, which, in turn, disturbs micelle formation inhibiting cholesterol absorption. Reduction in serum cholesterol level by oat-bran treatment has also been ascribed to an inhibition of the synthesis of endogenous cholesterol. However, a randomised study of 8 weeks' duration suggested that this was not the cause ${ }^{31}$.

While it is possible that the effects that oats exert on both endothelial function and serum or plasma cholesterol levels are solely attributable to the $\beta$-glucan (soluble fibre) content of the grain, alternative explanations include phytooestrogens, antioxidants, level of folate fortification, increased polyunsaturated fat intake, a glycaemic-loading benefit, and even a decreased $\mathrm{Na}$ intake as compared with refined grain sources such as bread ${ }^{28,29}$. In postmenopausal women, an oat-only treatment exerted an effect on flowmediated vasodilation closer to that of significance ${ }^{39}$; however, this was not observed elsewhere ${ }^{29}$. This may suggest that phyto-oestrogens exert a beneficial or protective action additional to that seen from the $\beta$-glucan components of the grain ${ }^{20}$. As vascular oestrogen receptors are considerably more abundant in women than men, a possible shift in the focus from the $\beta$-glucans present in oats to the phyto-oestrogen component of the grain warrants further investigation. 


\section{Phytochemicals}

The health benefits of oats are often attributed to the presence of various phytochemicals including PUFA, oligosaccharides, plant sterols and stanols, and saponins rather than the bulk components. Whole grains such as oats are important dietary sources of water-soluble and fatsoluble antioxidants that include vitamin E, tocotrienols, Se, phenolic acids and phytic acid. These antioxidants have a range of activities and stabilities and thus are available throughout the gastrointestinal tract over a long period after being consumed. The ability to isolate and purify bioactive phytochemicals is critical to their study ${ }^{45}$.

Knowledge concerning the biologically active minor components of oats has been summarised to $1998^{13}$. The range and diversity of bioactive compounds is vast and potentially ranges from simple low-molecular-weight volatile substances to polymeric species. Apart from those chemicals naturally present in oat grains, processed foods contain new compounds formed during processing and storage. For example, volatile Maillard reaction products, such as pyrazines, pyrroles and furans, are formed during processing operations ${ }^{46}$ and these species possess antioxidant activity ${ }^{47}$. However, the total amount of volatile compounds was higher in native (ungerminated) oat than in processed oat ${ }^{48}$, suggesting that processing induces significant changes in the oat. Quantitative data on phytochemicals often show great variability due to both sample and methodological variability. The effects of processing on the content and activity of potential phytochemicals is poorly characterised.

\section{Antioxidants}

The oat grain is rich in unsaturated lipids and lipolytic enzymes such as lipase and lipoxygenase ${ }^{17}$, rendering the PUFA and lipid-soluble vitamins in the grain susceptible to oxidation. It is not unexpected that natural selection has endowed the oat grain with a complement of endogenous antioxidants. Various chemicals protect the lipids in oat grains against oxidation. These bioactive compounds, which include tocopherols, L-ascorbic acid, thiol, phenolic amino acids and phenolic compounds ${ }^{49}$, protect the plant cells against the destructive activity of free radicals, a protective effect that is evidently transferred when the oat is consumed. Prospective population studies consistently suggest that when consumed in whole foods, antioxidants are associated with significant protection against CVD. The broad range of antioxidant activities from the phytochemicals abundant in whole grains is thought to play a strong role in their cardioprotective effects. The most abundant antioxidants in oats are vitamin E (tocols), phytic acid and phenolic compounds including avenanthramides, but flavonoids and sterols are also present ${ }^{50}$. These antioxidant compounds are typically concentrated in the outer layers of the kernel ${ }^{51}$ although in a study of four cultivars caffeic acid and the avenanthramides were predominantly found in groats, while many of the other phenols were present in greater concentrations in hulls ${ }^{52}$. Total phenolic contents of the four varieties of oats ranged from 209 to 294 and from 193 to $308 \mathrm{mg}$ gallic acid equivalents $/ \mathrm{kg}$ in the groats and hulls, respectively. The groats had significantly higher antioxidant activity than hulls.

When examining antioxidants, their chemical structure, concentration and activity are important considerations and the distinction between concentration or amount of an antioxidant and its activity is critical. Antioxidant activity is commonly evaluated using a diverse range of in vitro tests. These tests can be broadly classified into two categories based on their chemistry: hydrogen atom transfer reactionbased assays and single electron transfer reaction-based assays 53,54 .

Extraction of antioxidants from the oats is generally a prerequisite in any comprehensive analysis scheme for determination of either concentration or activity. The range of solvents that has been used for extraction of antioxidants from oats includes diethyl ether and acetone plus various alcoholic extractants ${ }^{55}$. For example, methanol and propan2-ol have been investigated for the recovery of antioxidants from milled oats ${ }^{56}$. The efficiency of the extraction was assessed by measuring the concentration of total phenolic compounds and the antioxidant activity based on $\beta$-carotene bleaching and chemiluminescence quenching. Although propan-2-ol extraction was less efficient in terms of recovery of activity, its advantages for industrial application were detailed. Residues from the usual aqueous-organic extraction typically contain a significant amount of hydrolysable phenols with a high antioxidant capacity (see later) that is usually ignored in the literature ${ }^{57}$.

Our studies revealed that the amount of extractable matter increased with the polarity of the extractant but that greatest activities were found in aqueous methanolic extracts. Extraction of different cereal grains with water and aqueous methanol confirmed these findings ${ }^{55}$. The water extract of oats showed no antioxidant activity as measured by 2,2'-azobis(2-amidinopropane) dihydrochloride (AAPH)-induced lipid oxidation in a liposome system but weak scavenging of the 2,2'-azino-bis(3-ethylbenzthiazoline-6-sulfonic acid) $\left(\mathrm{ABTS}^{+}\right)$radical. This weak activity was not correlated with total phenol content and it was suggested that it may originate from the combined activity of phenols and protein. Data for the methanolic extracts also suggested that antioxidant species other than the phenols must be considered to account for observed trends. A protein-rich oat extract reduced the initial oxidation rate of linoleic acid oxidation in an aqueous suspension containing lipoxygenase- $1^{58}$. The extract reduced the concentration of linoleic acid that acts as substrate for lipoxygenase-1 rather than acting on the enzyme itself.

Although the correlation of antioxidant activity of oatmeal, as measured by NO radical scavenging and $\beta$ carotene bleaching, with soluble fibre was relatively low $\left(R^{2}<0.6\right)^{59}$, a high correlation was observed between antioxidant activity and total phenolic compounds $\left(R^{2}\right.$ $0.99)$, flavonoids $\left(R^{2} 0.99\right)$ and anthocyanins $\left(R^{2}>0.98\right)$. The antioxidant activity of three commercial ethanolic extracts of oats plus a more hydrophobic propan-2-ol extract was measured by inhibition of human LDL oxidation and two free radical-quenching assays ${ }^{60}$. Despite the diversity of procedures, a general pattern of antioxidant activity emerged in which activity increased with increasing total phenolic content. Minor differences in relative activity were 
assigned to the reactivity preference of specific phenols towards different radical types. The correlation of activity with phenolic content is consistent with other studies ${ }^{61}$ and it appears that most of the antioxidant activity of oats resides with the hydrophilic components and particularly the phenolic fraction in the aleurone ${ }^{62}$. In this study, the contribution of oat tocols accounted for $<5 \%$ of the measured antioxidant capacity although it has been noted ${ }^{60}$ that the assumption of equivalent reaction rates between 6hydroxy-2,5,7,8-tetramethylchromane-2-carboxylic acid (Trolox) and tocols on which the calculation was based is not necessarily correct in all cases. However, the error introduced would not change the conclusion substantially, although a potentially more serious flaw is that such assessments are typically based on simple chemical measurements that may be useful in predicting behaviour of oat extracts for food uses (for example, as a natural food additive) but cannot accurately reflect the situation in the human body. The propanol extract in the above study ${ }^{60}$ was effective at quenching both aqueous soluble free radical species and the peroxyl species generated during lipid oxidation in LDL particles. This was attributed to the diverse mixture of antioxidants in the extract. The antioxidant species in oats can therefore be classified as lipophilic (for example, tocols) and hydrophilic (for example, phenols). These exhibit diverse partitioning behaviour that can provide synergistic protection to the grain and to consumers of oats.

\section{Tocols}

Vitamin E is a generic term for the eight tocols exhibiting the biological activity of $\alpha$-tocopherol. The tocols consist of four members each of tocopherol and tocotrienol (Fig. 1).

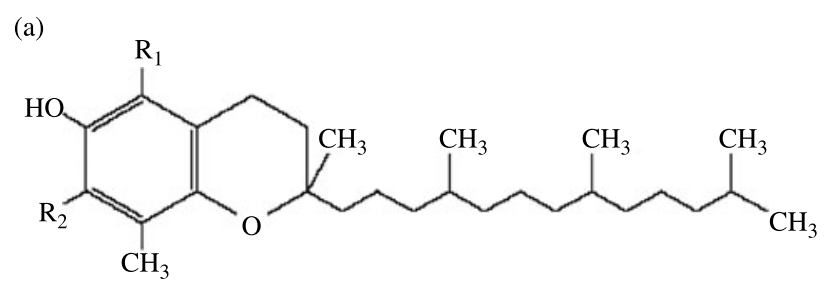

(b)

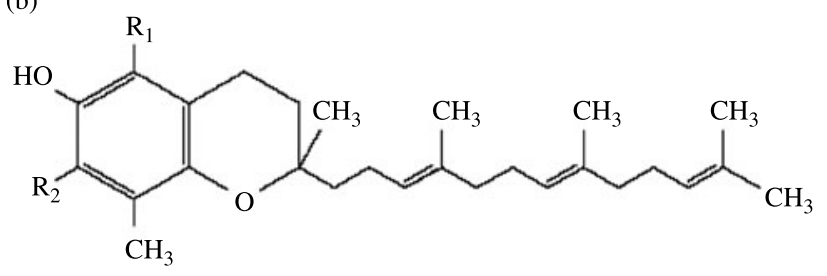

\begin{tabular}{lll} 
& \multicolumn{1}{c}{$\mathrm{R}_{1}$} & $\mathrm{R}_{2}$ \\
\cline { 2 - 3 }$\alpha$ & $\mathrm{CH}_{3}$ & $\mathrm{CH}_{3}$ \\
$\beta$ & $\mathrm{CH}_{3}$ & $\mathrm{H}$ \\
$\gamma$ & $\mathrm{H}$ & $\mathrm{CH}_{3}$ \\
$\delta$ & $\mathrm{H}$ & $\mathrm{H}$
\end{tabular}

Fig. 1. Structures of the tocols: (a) tocopherols; (b) tocotrienols.
These differ in the number and positions of methyl substituents on the phenolic ring. As they comprise neither isomers nor homologues, the term E-vitamers is sometimes used to describe them collectively.

Tocols are lipophilic and thus intimately associated with lipid components of the sample matrix. Sample preparation procedures for analysis involve either solvent extraction or saponification using alkaline hydrolysis ${ }^{63}$. The method has a significant effect and saponification has been shown to increase yield by $25 \%{ }^{64,65}$. Quantification can be achieved by GC or HPLC $66,67,68,69,70$. For GC sample saponification is usually employed to eliminate acyl lipids which would otherwise interfere. This preparation step is not critical in HPLC and separation has been achieved by reversed-phase systems using fluorescence detection. Separation of all eight species is not necessary in some situations since many foods do not contain the full complement of vitamers. However, the ability to resolve all vitamers is desirable for cereal samples and since separation of the $\beta$ - and $\gamma$-isomers of tocopherols and tocotrienols is difficult to achieve on most reversed-phase columns, normal-phase columns are also employed ${ }^{65,71,72}$.

In a survey of twelve oat genotypes, grown at three locations in the USA, the concentration of total tocols ranged from approximately 20 to $30 \mathrm{mg} / \mathrm{kg}$ but with variation due to both genetic and environmental factors ${ }^{73,74}$. Oat grains contain predominantly $\alpha$-tocotrienol with a lesser amount of $\alpha$-tocopherol and small amounts of the $\beta$-homologues ${ }^{75}$. In Italian trials, growing location exerted a strong influence on accumulation of tocols in the kernel ${ }^{71}$. The effects of processing and storage on tocol concentration in oats have been largely ignored. Total tocols in rolled oats were reported ${ }^{76}$ as $32 \mathrm{mg} / \mathrm{kg}$ with a distribution of vitamers similar to that of oat grain but in puffed oats the $\alpha$ tocotrienol concentration was lower. Degradation of tocols was observed during storage at room temperature and the rate was enhanced by exposure to air ${ }^{73}$. $\alpha$-Tocotrienol and $\alpha$-tocopherol degraded faster than the other vitamers during storage.

The distribution of tocols in the kernel is uneven. Tocotrienols are abundant in the bran fraction of the endosperm whereas the tocopherols are located almost exclusively within the germ ${ }^{71,73}$. The profile in hulls and groats is similar but with significantly higher concentrations in the latter ${ }^{77}$. These considerations are significant since the tocols differ in their biological activities. The uneven distribution in the kernel is important as oats are generally consumed as the whole grain. A positive correlation between tocotrienols and oil concentrations has been found in a range of oat varieties ${ }^{78}$. The tocol profile in the oil bodies reflected that in oat grain, with $\alpha$-tocotrienol accounting for approximately $66 \%$ of the total tocols ${ }^{79}$. An intrinsic association between the tocols and oil bodies was suggested in which the tocols provide oxidative stability to the membrane and/or oil of oat oil bodies. However, in a more recent trial, tocol and lipid concentrations were not correlated $^{64}$.

The tocol compositions of oat and barley are similar in that $\alpha$-tocotrienol is the predominant species in both cereals. Table 2 compares the tocol content of oat with that of barley, and whilst barley contains all eight tocols, the $\gamma$ - and 
Table 2. Tocol contents ( $\mathrm{mg} / \mathrm{kg}$ dry matter) of oat and barley as measured by high-performance liquid chromatography and total tocols obtained by absorption measurement ${ }^{65,71,73}$

\begin{tabular}{lrrrrrrrrr}
\hline & $\alpha-T$ & $\beta-T$ & $\gamma$-T & $\delta$-T & $\alpha$-T3 & $\beta$-T3 & $\gamma$-T3 & $\delta$-T3 & Total tocols \\
\hline Oat & 14.9 & 3.0 & 0.4 & - & 56.4 & 5.4 & - & - & 72.1 \\
Oat & 7.0 & 0.8 & nd & nd & 27.8 & 3.1 & nd & nd & - \\
Groats, dried & 20.0 & 10.9 & 3.4 & nd & 55.7 & 5.0 & 0.6 & 4.4 & 40.9 \\
Oats, rolled & 17.1 & 9.5 & 3.5 & nd & 60.1 & 6.9 & nd & 2.9 & 28.3 \\
Barley & 8.6 & 0.9 & 5.6 & 0.7 & 40.3 & 8.7 & 10.4 & 0.9 & 74.7 \\
\hline
\end{tabular}

T, tocopherol; T3, tocotrienol; nd, not detected.

$\delta$-vitamers are found in oats in trace amounts if at all ${ }^{80}$. However, closer examination of oats may yet reveal further tocols, as some novel species have been identified in rice ${ }^{81}$. Indeed, the situation has not changed dramatically since 1993 when Balandrin et al. ${ }^{82}$ estimated that at least $85 \%$ of the world's estimated 250000 species of higher plants had not been adequately surveyed for potentially useful bioactivity.

\section{Carotenoids}

Carotenoids are a diverse group of yellow orange pigments that are also associated with the lipidic fractions. They can be divided into two classes as carotenes and xanthophylls which share a common structural feature of a conjugated carbon-carbon double-bond aliphatic system. Analytical methods for their determination in oats ${ }^{63}$ are well documented, including problems associated with the preparation of suitable standards ${ }^{83}$. Carotenoid data have been obtained historically by measuring total absorption at a specified wavelength, and many currently available tables of food composition data are still expressed as $\beta$-carotene, $\beta$-carotene equivalents, or retinol equivalents.

Cereals are not a major dietary source, as reflected in the limited data on cereal carotenoids. Amongst the cereals, oats have a relatively low carotenoid content. Lutein with a concentration of $0.23 \mathrm{mg} / \mathrm{kg}$ (oat dry weight) was the major carotenoid of oats and also of other cereals ${ }^{63}$, with lesser amounts of zeaxanthin and $\alpha$-plus $\beta$-carotene.

\section{Phytic acid}

Phytic acid, which has an established antioxidant function ${ }^{84}$, has been measured in oats. Concentrations reported in a number of studies ranged $5 \cdot 6-12.7 \mathrm{~g} / \mathrm{kg}^{44,85,86,87}$, with variation due to available soil $\mathrm{P}$ and other environmental factors ${ }^{44,88}$. Data have been reported for both oats and groats but are insufficient to draw conclusions about relative levels. Apart from its antioxidant activity, phytate can complex with essential mineral nutrients, thereby reducing their bioavailability ${ }^{85}$. However, phytate can be degraded by activating endogenous phytases during processes such as soaking, blanching and fermentation ${ }^{89}$.

\section{Phenols}

The bioavailability and antioxidant capacity of oat phenols have been reviewed ${ }^{90}$. Phenols in oats may be classified in various ways such as free $v$. bound but we have chosen to distinguish simple phenols (for example, phenolic acids such as caffeic acid) from the avenanthramides and the polymeric lignins (derived from lignans). Structurally, lignins are related to the simple phenols in that they are heterochain co-polymers produced from oxidative crosslinking of phenolic alcohols of the guaiacyl, syringyl and $p$-coumaryl types ${ }^{91}$. Lignins provide strength to the cells but they also exhibit antioxidant behaviour. The data on these materials in oats are too limited to reach any conclusions about their bioactivity other than to identify the need for further work.

Analytical methods for phenols are well documented ${ }^{92,93,94,95,96}$ and usually involve alcoholic extraction of the ground groats or hulls followed by HPLC using gradient elution and reversed-phase systems. Detection typically involves UV absorption although electrospray ionisation $\mathrm{MS}^{97}$ is becoming increasingly common ${ }^{98}$. A major analytical challenge is the diversity of phenolic species and the absence of commercial standards particularly for the more complex species. Guth \& Grosch ${ }^{99}$ compared the stable-isotope dilution assay with a conventional method for the determination of both free and esterified caffeic and ferulic acids in oatmeal. The conventional approach detected $84 \%$ of the ferulic acid but only $32 \%$ of the caffeic acid, which was more susceptible to oxidation than the former.

Total phenols (Folin-Ciocalteu), total anthocyanins and total flavonoid contents of Polish oats were 196.1, 835 and $177 \mathrm{mg} / \mathrm{kg}$ (dry weight), respectively ${ }^{59}$. In a study of three cultivars grown in the USA, the total phenols were 275,310 and $323 \mathrm{mg} / \mathrm{kg}^{100}$. Simple phenols and avenanthramides measured by HPLC accounted for approximately 30-40\% of the total phenols. This result is not surprising as it is well known that the Folin-Ciocalteu method overestimates the total phenol content due to non-specificity of the reagent. An important distinction is that the term 'total' refers to the phenolic content as determined by a colorimetric procedure. The terms 'free' and 'bound' are used loosely to refer to the availability or extractability of an individual phenol or phenolic class. Thus, one can refer, for example, to total free phenols or total bound phenols or the result obtained by summation of both groups.

\section{Free v. bound phenols}

Phenols may occur as the free compounds, or as soluble conjugated and insoluble bound forms. Soluble phenols include ester-linked glycerol conjugates, ether- or esterlinked glycosides, anthranilic acids and avenanthramides, 
flavonoids and ester-linked alkyl conjugates ${ }^{60}$, and the bioavailability of these compounds depends on their partitioning behaviour among other things. The distribution between free, soluble and bound forms of phenolic compounds in cereals has been reported as 6, 17-30 and $66-80 \%$, repectively ${ }^{60}$, but with wide variations between different cereals and depending on the fractionation method employed. Thus, phenolic compounds are rarely found in the free form in cereals; the majority are bound via covalent link with cell-wall polysaccharides. In whole oat grains, free phenols accounted for $25 \%$ of the total, while the remaining $75 \%$ were in the bound form ${ }^{101}$. Traditionally, analytical methods have emphasised the measurement of the free phenols, and these methods have been applied directly and indiscriminately to whole grains. Free phenols comprise approximately $70-80 \%$ of the total phenolics content in common fruits and vegetables such as apples, red grapes, broccoli and spinach ${ }^{101}$. In this way, the amount and activity of antioxidants in whole grains have been vastly underestimated. The importance of analytical science and methodology is underlined by these studies. As previously stated $^{102}$, 'Every progress in methodology is a progress in science.'

In vitro release of the free phenols from the covalently bound species requires severe conditions, but relatively little is known about their bioavailability and their behaviour in the body where fermentation in the gastrointestinal tract may produce active metabolites. These findings regarding bound $v$. free phenols may help explain the contradictory results of population studies and short-term clinical trials. The latter yield inconsistent results, whereas populations eating diets high in fibre-rich whole grains consistently have lower risk for CVD and colon cancer. Anderson ${ }^{19}$ noted that it is the synergistic effect of whole grains that is important, and in this respect the oat grain is exceptional in that dehulling does not remove the essential nutrients.

\section{Simple phenols}

The predominant simple phenols in oats are the phenolic acids but these are generally detected in low concentrations $(<5 \mathrm{mg} / \mathrm{kg})$ if at all in free forms ${ }^{50-52,100,103,104}$. Significantly higher levels were reported in a study of oats grown in the USA but extraction was conducted over $7 \mathrm{~d}^{105}$. Concentrations of individual phenolic acids of four varieties of oats ranged $0.3-2.4 \mathrm{mg} / \mathrm{kg}$ in groats and $0.6-9.7 \mathrm{mg} / \mathrm{kg}$ in hulls with significant differences due to cultivar ${ }^{52}$, growing location $^{100}$ and oat ripeness ${ }^{106}$. An unidentified flavan-3-ol had a higher concentration of approximately $25 \mathrm{mg} / \mathrm{kg}$ in both groats and hulls whilst a number of avenanthramides were tentatively identified with approximate concentrations of 2 and $6 \mathrm{mg} / \mathrm{kg}$ in groats and hulls, respectively ${ }^{52}$.

In contrast with the free phenolic acids, significant quantities of bound phenolic acids are obtained following acidic or alkaline hydrolysis of samples (Table 3), although the levels are significantly lower in oat products than in other cereals ${ }^{103,107,108}$. Between seven and nine phenolic acids are commonly detected in oats ${ }^{104}$ but ferulic acid was dominant $^{77,103,105}$. The distribution of ferulic acid between free, soluble conjugated and bound forms in oat grains was $0.4,1.8$ and $97.8 \%{ }^{101}$. Hydroxycinnamates such as ferulic acid exist in $\mathrm{Z}$ (cis) and $\mathrm{E}$ (trans) forms, with strong evidence that the E-isomer is the naturally occurring form. However, the isomers are light sensitive and generally undergo isomerisation during extraction ${ }^{109}$.

Flavonoids such as kaempferol and quercetin constitute a significant part of the antioxidant fraction of most foods, and total flavonoids in oats were reported as $177 \mathrm{mg} / \mathrm{kg}$ based on colorimetric measurement ${ }^{59}$. Total flavonoid content has been reported elsewhere ${ }^{101}$ but data for individual flavonoids in oats are limited ${ }^{110}$, probably due to the fact that other foods constitute a much richer source of these substances. Flavonoids were not detected in oats using a spray reagent ${ }^{111}$.

The bioavailability of phenols in an oat extract was tested in hamsters by measurement of plasma concentrations ${ }^{15}$. HPLC of the extract revealed about thirty peaks with detectable redox potential, and nine of these peaks were identified as phenolic acids and avenanthramides. Among identified phenols, avenanthramides were present at highest concentrations in the oat extract but the lowest concentrations in hamster plasma. Pharmacokinetic data established maximum plasma concentrations of 0.10 to $1.55 \mu \mathrm{mol} / 1$ and 0.03 to $0.04 \mu \mathrm{mol} / 1$ for the phenolic acids and avenanthramides, respectively. The ex vivo resistance of hamster LDL to $\mathrm{Cu}^{2+}$-induced oxidation was not altered by the absorbed phenols, but in vitro addition of ascorbic acid to the oat extract synergistically extended the oxidation lag time by $58 \%$. The extract also increased the in vitro lag time of human LDL oxidation in a dose-dependent manner $(P<0.0001)$ with a synergistic effect on addition of vitamin $\mathrm{C}$.

Table 3. Phenolic acid contents of oat products ${ }^{52,103}$

\begin{tabular}{|c|c|c|c|c|c|c|c|c|c|}
\hline \multirow[b]{2}{*}{ Sample } & \multicolumn{9}{|c|}{ Concentration (mg/kg DM) } \\
\hline & I & II & III & IV & V & VI & VII & VIII & IX \\
\hline Oat bran* & 5.9 & 363 & 99 & ND & 26 & 13 & 24 & 31 & 154 \\
\hline Oat flakes, whole grain* & 3.9 & 275 & 57 & ND & 19 & ND & 18 & 22 & 121 \\
\hline Oats† & $1 \cdot 1$ & 1.3 & 0.5 & 1.4 & $2 \cdot 6$ & $4 \cdot 0$ & $2 \cdot 2$ & $\ddagger$ & 1.3 \\
\hline Groats† & $2 \cdot 4$ & 1.2 & 0.5 & 0.7 & 1.6 & 0.9 & 0.3 & $\ddagger$ & $1 \cdot 2$ \\
\hline Hulls† & 0.9 & 1.7 & 0.6 & $2 \cdot 1$ & $4 \cdot 0$ & $9 \cdot 7$ & $7 \cdot 7$ & $\ddagger$ & 1.7 \\
\hline
\end{tabular}

I, caffeic acid; II, ferulic acid; III, sinapic acid; IV, protocatechuic acid; V, vanillic acid; VI, p-coumaric acid; VII, p-hydroxybenzoic acid;

VIII, syringic acid; IX, ferulic acid dehydrodimers; ND, not detected.

* Bound phenols obtained after hydrolysis.

†Free phenols.

$\ddagger$ Not measured. 
Dehydrodimers of ferulic acid constitute an important fraction of the phenolic content of oats ${ }^{103}$. Ferulic acid and, to a much lesser extent, $p$-coumaric and possibly sinapic acid acylate cell-wall polysaccharides. Monomeric ferulates are covalently cross-linked to polysaccharides by ester bonds and to components of lignin mainly by ether bonds ${ }^{112,113}$. Diferulates that link two polysaccharide chains together can become involved in the lignification process to produce a highly cross-linked lignin-polysaccharide network $^{114,115,116,117,118}$. The 'unique' function of ferulate in polymer cross-linking has been examined ${ }^{119}$. These ferulate cross-linked polysaccharides are an important structural component of cell walls of cereals ${ }^{120,121}$ and hence of dietary fibre.

The dehydrodiferulates were components of insoluble dietary fibre with a concentration of $3599 \mathrm{mg} / \mathrm{kg}$ in this fraction $^{121}$. Other reported results ${ }^{103,113}$ are comparable with this value particularly when the limitations of methodology are considered ${ }^{121}$. In contrast, the concentration of dehydrodiferulates in soluble dietary fibre was $38 \mathrm{mg} / \mathrm{kg}$. The arabinoxylans of the insoluble dietary fibre of oats were approximately ten times more cross-linked than arabinoxylans of soluble dietary fibre. Extensive crosslinking may influence the physiological properties of dietary fibre of oats or other cereals. There is evidence of the bioavailability of the diferulates ${ }^{122}$, which may also be important due to their antioxidant activities.

In the plant, mechanisms for the cross-linking of cell-wall polymers involve photochemical dimerisation or radical dehydrodimerisation of the hydroxycinnamates ${ }^{123,124,125}$. For many years, the sole ferulic acid dehydrodimer known was the $5-5^{\prime}$-coupled diferulate based on photochemical dimerisation. However, it was shown that the dominant mechanism for cross-linking feruloylated polysaccharides was free radical coupling leading to dehydrodiferulates and dehydrotriferulates ${ }^{126}$. Radical coupling via the action of cell wall-bound peroxidases produced several regio-specific diferulates ${ }^{127}$. The full range of diferulates includes the $8-5^{\prime}-, 8-O-4^{\prime}-, 5-5^{\prime}-, 8-8^{\prime}-$ and $4-O-5^{\prime}$-coupled diferulates and, with the exception of the last-named isomer, all diferulates were identified in insoluble dietary fibre and at much reduced levels in soluble dietary fibre ${ }^{121}$. However, some of these isomers may be artifacts arising from saponification during the extraction procedure ${ }^{125}$.

\section{Avenanthramides}

Avenanthramides are found exclusively in oats. Chemically, avenanthramides are amides of different cinammic acids with different anthranilic acids ${ }^{128}$. They are distinguished based on their particular anthranilic acid component which may include anthranilic, 5-hydroxy-anthranilic, 5-hydroxy4-methoxy-anthranilic or 4-hydroxy-anthranilic acids ${ }^{129}$. Avenathramides composed of anthranilic acid and 5-hydroxy-anthranilic acids are referred to as group 1 and 2 , respectively. Further classification is derived from their cinnamic acid component, and may include $p$-coumaric, caffeic or ferulic acids, which are denoted as p, c and f, respectively. Alternative nomenclature has been used in the literature, for example ${ }^{130,131}$. Avenanthramides-2p $(N$ (4'-hydroxycinnamoyl)-5-hydroxyanthranilic acid), 2c
( $N$-(3', $4^{\prime}$-dihydroxycinnamoyl)-5-hydroxyanthranilic acid) and -2f ( $N$ - $\left(4^{\prime}\right.$-hydroxy-3'-methoxycinnamoyl)-5-hydroxyanthranilic acid) (Fig. 2) are the most commonly investigated since they consistently appear in higher concentrations in oat extracts ${ }^{129,130}$. In fact, avenanthramide- $2 \mathrm{c}$ constitutes about one-third of the total avenanthramide content in oat grain ${ }^{132}$.

Avenanthramides constitute by far the major unbound phenolic antioxidants present in the oat kernel, including the bran and sub-aleurone layers (cited in Nie et al. $^{132}$ ). Nevertheless, total concentrations of avenanthramides in oats are small, ranging from 2 to $289 \mathrm{mg} / \mathrm{kg}$ (cited in Jastrebova et al. ${ }^{129}$ ). Bryngelsson et al. $^{77}$ investigated antioxidants in the groats and hulls of seven Swedish oat varieties and found that differences in the chemical composition between groats and hulls were not consistent, and that the chemical composition of hulls cannot be predicted by knowing the composition of groats and vice versa. In fact, avenanthramide content was only related to total lipids in the hulls. In all seven varieties, total avenanthramide content was higher in groats compared with hulls, with average concentrations of $13.7 \pm 4.3$ and $5.9 \pm 3.8 \mathrm{mg} / \mathrm{kg}$ DM, respectively. Similarly, total antioxidant capacity was generally higher in groats than in hulls. With respect to oat groats, Peterson et al. ${ }^{61}$ have shown that avenanthramides are more uniformly distributed within the groat compared with simple phenolic acids, and that concentrations of avenanthramides were not correlated with pearling processing time.

The avenanthramide content of three commonly consumed oat products has also been investigated: oat flakes, whole grain; oat flakes, pre-cooked whole grain; oat bran ${ }^{103}$. Total avenanthramides (avenanthramides-2c, $-2 \mathrm{p}$ and $-2 \mathrm{f}$ ) content in oat flakes was $27 \mathrm{mg} / \mathrm{kg}$ fresh weight and $26 \mathrm{mg} / \mathrm{kg}$ fresh weight in the whole grain and pre-cooked whole grain, respectively. These results are double that found in the oat bran (13 mg/kg fresh weight). Such results may be explained by the different raw materials used in the production of the flakes and bran, and the fact that oat brans are not particularly enriched by avenanthramides compared with flakes ${ }^{103}$.
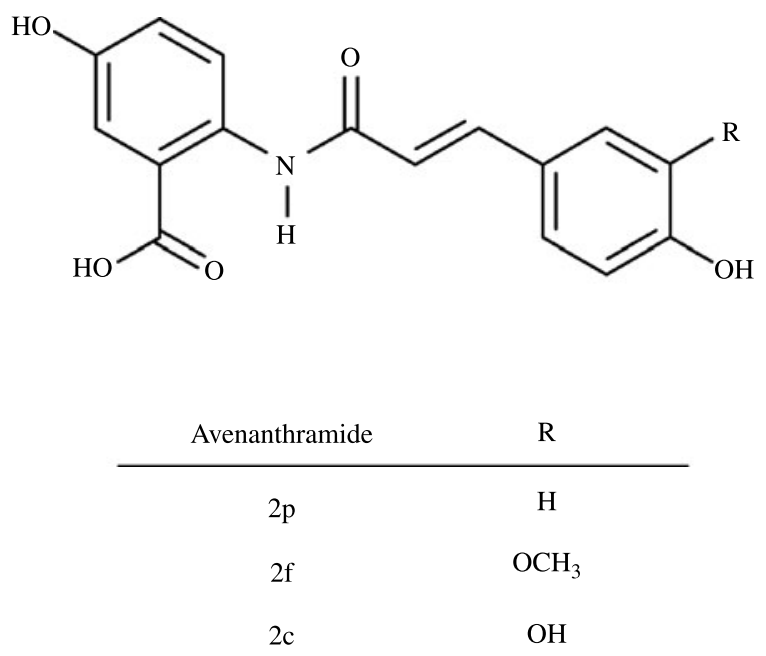

Fig. 2. Structure of avenanthramides. 
High levels of avenanthramides in oats were significantly correlated with freshness, low rancidity and bitterness, while the opposite was found for most other simple phenols that were investigated ${ }^{133}$. Dimberg et al. ${ }^{134}$ have examined the impact of a variety of environmental, processing and storage conditions on avenanthramide contents in various oat products, and concentrations of avenanthramides in oats were cultivar dependent. Emmons \& Peterson ${ }^{100}$ reported significant cultivar $\times$ location interactions on the avenanthramide content (2c, 2f, $2 p$ ) of oats. Significant differences in avenanthramide concentrations as a result of growing year and application rate of $\mathrm{N} / \mathrm{ha}$ have also been observed $^{133}$; however, differences in the avenanthramide concentration of oats grown using either organic or conventional cropping systems were not found ${ }^{133}$.

Bratt et al. ${ }^{135}$ have investigated the structure-antioxidant activity relationships of eight avenanthramides. All avenanthramides were synthesised in light of the difficulties associated with isolation and recoveries of these compounds, and were amides of anthranilic acid and 5hydroxyanthranilic acid with the common cinnamic acids $p$-coumaric, caffeic and ferulic; however, sinapic acid was also included. Antioxidant activity was evaluated using two commonly employed approaches; reactivity towards 2,2diphenyl-1-picrylhydrazyl (DPPH; a hydrophilic, polar system) and linoleic acid (a lipophilic, non-polar system). Both methods aim to determine $\mathrm{H}$ atom transfer efficiency from the phenol to a radical. Results for both antioxidant assays showed that the initial relative reactivity of the cinnamic acids decreased in the same order such that sinapic $>$ caffeic $>$ ferulic $>p$-coumaric acid. This same trend was observed for the corresponding avenanthramides in the DPPH system, but not for the linoleic acid system. This discrepancy is not surprising since it is known that results can vary among in vitro antioxidant assays as a result of the different chemistries and conditions used ${ }^{50,135}$.

Peterson et al. ${ }^{130}$ tested the in vitro antioxidant activity of synthetically produced avenanthramides $2 \mathrm{c}, 2 \mathrm{p}$ and $2 \mathrm{f}$. The tests used to measure antioxidant activity included inhibition of $\beta$-carotene bleaching, and reaction with the free radical DPPH. In the $\beta$-carotene-bleaching assay, the order of effectiveness was such that $2 \mathrm{c}>2 \mathrm{f}>2 \mathrm{p}$ in accordance with other results ${ }^{135}$. Comparison of the concentrations of avenanthramides that caused a $50 \%$ inhibition in $\beta$-carotene bleaching $\left(\mathrm{EC}_{50}\right)$ relative to the antioxidant butylated hydroxytoluene showed $2 \mathrm{c}$ to be $2 \cdot 4-$ fold higher, $2 \mathrm{f} 15$-fold higher and $2 \mathrm{p}$ 62-fold higher. For the DPPH assay, the relative effectiveness of the antioxidants at the $50 \%$ reduction level was identical to that observed for the $\beta$-carotene bleaching. However, compared with the antioxidant Trolox, the order of effectiveness was such that $2 c>2 f>$ Trolox $>2 p$. The relative reactivities of the three avenanthramides again reflected the antioxidant activities of their constituent hydroxycinnamic moieties.

It is apparent that avenanthramide- $2 \mathrm{c}$ contributes significantly more to the total antioxidant activity measured in oat groats compared with other avenanthramides and as such has the most potential for in vivo effects. Indeed, Ji et al. ${ }^{136}$ have found that the inclusion of avenanthramide-2c in rat diets altered oxidant-antioxidant balance in various tissues. Administration of avenanthramide-2c selectively attenuated exercise-induced reactive oxygen species production and lipid peroxidation in rats. This has been related to the ability of the avenanthramide to influence tissue antioxidant enzyme systems such as superoxide dismutase and glutathione peroxidase activities. The authors therefore recommend avenathramide- $2 \mathrm{c}$ as a potential dietary antioxidant supplement; however, its bioavailability, specific distribution and tissue concentrations in response to oral supplementation and exercise need to be further characterised.

The anti-atherogenic activity of avenanthramides has been investigated in vitro ${ }^{137}$. Avenanthramides were found to exhibit a high capacity to inhibit adhesive interaction between endothelial cells through inhibition of adhesion molecule expression and to inhibit pro-inflammatory cytokines and chemokines. Such species are important in the recruitment of immune cells and leucocytes to the site of inflammation. The authors postulate that, potentially, the mechanism for antioxidant inhibition of pro-inflammatory cytokines, chemokines, adhesion molecules, and human aortic endothelial cell adhesions to monocytes is mediated through inactivation of the NF-кB signalling pathway. Avenanthramides have also been shown to be bioavailable in hamsters, and interact synergistically with vitamin $\mathrm{C}$ to protect LDL during oxidation ${ }^{15}$. The latter results were based on in vitro experiments only, in that oat phenols including avenathramides did not enhance ex vivo resistance of LDL to oxidation. Oat phenols increased the lag time to LDL oxidation in a dose-dependent manner, and lag times were increased synergistically by combining oat phenols with vitamin $\mathrm{C}$. There is a general consensus that further research is needed to elucidate the mechanisms that underpin avenathramide bioactivity including anti-inflammatory and antioxidant activities, particularly in vivo ${ }^{15,137}$.

The need for more sensitive and selective methods for determining avenanthramides is apparent, as is the need to isolate and identify unknown avenanthramides occurring in trace quantities in oats ${ }^{129}$. For example, sinapic acid is also found in oats, yet it is not known whether avenanthramides derived from this cinnamic acid exist ${ }^{135}$. Avenanthramide determination is hindered due to the lack of commercially available reference standards. Mattila et al. ${ }^{103}$ have therefore published response factors for each avenanthramide compared with the structurally similar tranilast ( $N$-(3', $4^{\prime}$-dimethoxycinnamoyl)anthranilic acid). Response factors relate to measurement at $350 \mathrm{~nm}$ based on analysis using HPLC with diode array detection. Response factors were $1.15,1.42$ and 1.37 for avenanthramides-2c, $-2 p$ and $-2 f$, respectively. Improved analytical capabilities for avenanthramide determination will enable more accurate assessment of dietary intakes and facilitate production of prescribed diets by breeding of avenathramide-rich oat varieties.

\section{Lignans}

Lignans are diphenolic compounds which form the building blocks for lignin, a major component of plant cell walls. A limited number of food matrices has been comprehensively profiled for lignan analytes ${ }^{138}$. The available databases are generally based solely on secoisolariciresinol and 
matairesinol and largely underestimate quantities of lignans in foods. Thus, the overall level of lignan exposure that is important in relation to health and disease is not known ${ }^{139}$. A recent study ${ }^{140}$ comprehensively surveyed the lignan content of cereals, oilseeds and nuts.

Lignans in grain are concentrated in the outer fibrecontaining layers $^{141}$. Milling of oats would therefore have considerable impact on lignan content. For example, levels of secoisolariciresinol and matairesinol measured in oat bran were found to be 238 and $1550 \mu \mathrm{g} / \mathrm{kg}$, respectively, compared with 134 and $3 \mu \mathrm{g} / \mathrm{kg}$, respectively, in oat meal $^{141}$. Intake of wholegrain cereals is therefore advocated, and in a Danish study of 857 postmenopausal women, blood levels of enterolactone were significantly higher in women consuming the most whole grains ${ }^{142}$. Concentrations of lignans in oats are comparatively lower compared with other grains. Compared with the whole meal of rye, wheat, barley, maize and rice, the content of secoisolariciresinol was lowest in oats $(80 \mu \mathrm{g} / \mathrm{kg} \mathrm{DM})$ while matairesinol was present in oats in only trace amounts ${ }^{143}$.

Lignans have been reported to induce a wide range of bioactivities $^{140}$ that includes action as phyto-oestrogens, together with the isoflavones and coumestans. Collectively, phyto-oestrogens are defined as plant-derived compounds having an oestrogenic effect ${ }^{144}$. Plant lignans do not have inherent oestrogenic activity ${ }^{145}$ but are converted by a range of intestinal bacteria to more bioactive mammalian lignans (also referred to as enterolignans). Upon ingestion, sugar moieties are hydrolysed and it is the released aglycones which are metabolised by bacteria in the gut to the enterolignans ${ }^{139}$. Dietary phyto-oestrogens such as lignans may also be weakly anti-oestrogenic ${ }^{146}$. For example, enterolactone exhibits a biphasic nature in vitro and in vivo ${ }^{138}$ and may act as a weak oestrogen agonist or antagonist due to its structural similarity to that of endogenous oestrogens ${ }^{138}$.

Lignans have an antioxidant activity and although this activity has not been addressed in oats, Kitts et al. ${ }^{147}$ have investigated the in vitro antioxidant activities of secoisolariciresinol diglycoside and its mammalian lignans, enterodiol and enterolactone. The hydroxyl and peroxyl radicalscavenging capabilities of the lignans were assessed in lipidic and aqueous models, and tests included lipid oxidation in a linoleic acid emulsion system, degradation of deoxyribose by hydroxyl radicals to assess site-specific and non-site-specific scavenging activities, and plasmid DNA-nicking assay. All three lignans were similarly effective in lowering lipid peroxidation; however, both mammalian lignans were more effective than secoisolariciresinol diglycoside in reducing deoxyribose oxidation and DNA strand breakage. The results indicate a structureactivity difference between the three lignans with respect to antioxidant activity, and potentially structure-function differences between plant and mammalian lignans.

\section{Other phytochemicals}

Oats contain a number of other classes of phytochemicals including sterols, stanols and saponins. These compounds share a common origin from the isoprenoid pathway. The dedicated pathway to sterol synthesis occurs at the squalene stage $^{148}$. Cereals are recognised as significant sources of sterols and several sterols ${ }^{149}$ have been reported in oats (Table 4). The total sterol content in Finnish oat varieties was $447 \mathrm{mg} / \mathrm{kg}^{149}$, with $\beta$-sitosterol as the major sterol and with $\Delta 5$-avenasterol, brassicasterol and campesterol also present in significant quantities $149,150,151,152,153$. These four compounds constituted approximately $85 \%$ of the total sterols and all are 4-desmethylsterols ${ }^{149}$. Other sterols such as saturated stanols and 4-monomethyl- and 4-dimethylsterols $^{154}$ usually occur in much lower amounts. Sterol levels in rolled oats were at expected levels when compared with the corresponding grains, suggesting that processing operations do not significantly impact on sterols.

Other published data ${ }^{154}$ are in general agreement with sterol levels reported by Piironen et al. ${ }^{149,155}$. Discrepancies where they do occur may be attributed to differences in analytical procedure or to real differences in the samples. Sterols occur in cereals as free sterols and in conjugated form, that is, steryl esters of fatty or phenolic acids, steryl glycosides and acylated steryl glycosides ${ }^{156}$. The effect of extraction solvent and temperature on levels of free sterols and various conjugated forms in ground oats were investigated $^{80}$. Whilst levels of free sterols, steryl fatty acyl esters, steryl glycosides and acylated steryl glycosides were comparable, ferulated steryl esters were not detected. In many cases, reported data are limited to free sterols and their esters due to analytical limitations. However, steryl glycosides comprise a significant part of the total sterol content in oats and other cereals ${ }^{149}$. Liberation of the free sterols from their glycosides can be achieved by acid or enzymic hydrolysis. In this manner, total sterol content can be measured but it inevitably results in the loss of information content from the sample. On the other hand, exhaustive extraction of sterols without prior hydrolysis enables analysis of the intact steryl ferulates. Steryl ferulates were detected in wheat and rye fractions using this approach but not in oatbran ${ }^{156}$.

The saponins have attracted considerable interest as a result of their diverse properties, both beneficial and deleterious. They are a group of glycosides synthesised from mevalonic acid via the isoprenoid pathway and are derived from triterpenoid or steroid cyclisation products of 2,3-oxidosqualene ${ }^{157}$. Methods for their determination in plants $^{158,159}$ and oats ${ }^{160,161}$ are well characterised. They can be classified into two groups based on the nature of their aglycone skeleton. The first group is comprised of the

Table 4. Sterol contents of oats ${ }^{149,154}$

\begin{tabular}{lc}
\hline Sterol & $\begin{array}{c}\text { Sterol } \\
\text { concentration } \\
(\mathrm{mg} / \mathrm{kg} \mathrm{DM})\end{array}$ \\
\hline Brassicasterol & 34 \\
Campesterol & $40-44$ \\
Campestanol & Trace \\
Stigmasterol & $15-18$ \\
Sitosterol & $277-303$ \\
Sitostanol & 10 \\
$\Delta 5$-Avenasterol & $33-35$ \\
$\Delta 7-$ Avenasterol & 11 \\
Other sterols & $32-39$ \\
\hline
\end{tabular}


steroidal saponins and the more common triterpenoid saponins comprise the second group ${ }^{162}$. With the exception of oats, cereals and grasses are generally deficient in saponins. Members of the genus Avena synthesise the two different classes of saponins; the steroidal avenacosides which accumulate in the leaves and the triterpenoid avenacins in the roots.

The physiological activity and role of sterols and stanols in human health have been extensively reviewed $^{163,164,165,166,167,168,169}$ and, in the case of saponins ${ }^{157,162,170,171}$, a number of papers have specifically addressed the activities of oat saponins ${ }^{160,172,173,174,175,176}$. Saponins generally exhibit haemolytic properties and are toxic to cold-blooded animals. Their surface active properties distinguish this group of phytochemicals. Sparg et al. ${ }^{162}$ state that 'they are believed to form the main constituents of many plant drugs and folk medicines, ... consider saponins and polyphenols key ingredients in traditional Chinese medicines, and are responsible for most of the observed biological effects.' Lipid metabolism in slightly hypercholesterolaemic subjects was affected by simultaneous intake of stanol esters and $\beta$-glucan ${ }^{177}$. The addition of both components to dietary muesli lowered LDL-cholesterol more than either component alone although the reduction was less than predicted.

\section{Phytochemical stability}

The main commercially available derived products of oats are rolled oats, wholemeal, sifted flour and bran. The oat grain is inherently unstable once it is ground or flaked due to its relatively high oil concentration and high lipase activity. Hence, commercial processing exposes the grains to hydrothermal processes such as steaming, autoclaving or drum drying before flaking in order to inactivate enzymes. Hydrothermal processes may impact stability of the various phytochemicals. The commercial products are used in breakfast cereals or further processed for use as ingredients in a variety of breads, infant formulas and snacks. Changes in concentration and bioactivity ${ }^{178}$ may occur during each of these steps and/or during storage. For example, degradative losses of approximately $50 \%$ of phenolic compounds may occur during extrusion ${ }^{49}$. However, commercial products generally retain significant amounts of phytochemicals such as antioxidants ${ }^{179}$ although there are vast differences in relative stability between and even within the various classes of phytochemicals ${ }^{180}$. Moreover, breakdown of cell structures during commercial processing may enhance bioavailability and degradation of phytochemicals. Indeed, a proportion of oat antioxidants appears to be heat labile as suggested by greater activity of non-steam-treated green oats $^{62}$. For example, levels of vanillic acid, vanillin and, especially, $p$-coumaric acid, $p$-hydroxybenzaldehyde and coniferyl alcohol increased significantly in oat samples processed with hulls, but not in samples processed without hulls ${ }^{134}$. Ferulic acid increased in both processes, while caffeic acid and the avenanthramides were found to decrease during processing. Levels of phenolic acids generally increased during storage of unprocessed samples for 1 year; this increase was most pronounced after storage at high relative humidity.
The effect of various commercial hydrothermal processes (steaming, autoclaving, and drum drying) on levels of selected oat antioxidants varied with the nature of both the process and the antioxidant ${ }^{180}$. For instance, moderate losses of tocotrienols, caffeic acid and avenanthramide- $2 p$ occurred after steaming and flaking of dehulled oat groats, while ferulic acid and vanillin increased. The tocopherols and the avenanthramides- $2 \mathrm{c}$ and $-2 \mathrm{f}$ were not affected by steaming. In contrast, drum drying of steamed rolled oats resulted in a large decrease in total cinnamic acids and avenanthramides and almost complete loss of tocopherols and tocotrienols. Less-pronounced losses were observed when the same process was applied to wholemeal made from groats. Avenanthramide concentrations exhibited a time- and temperature-dependent increase when intact raw groats were steeped ${ }^{181}$. The increase in avenanthramide concentration following processing has been attributed to de novo synthesis, release of bound forms or an increased extractability after processing ${ }^{182}$. The whole grain structure was required as no concentration increase was observed when groats were milled before steeping ${ }^{181}$.

\section{References}

1. United States Department of Agriculture (2007) Oat facts. http://www.gramene.org/species/avena/oat_facts. html (accessed March 2007).

2. Gibson L \& Benson G (2002) Origin, history, and uses of oat (Avena sativa) and wheat (Triticum aestivum). http://www.agron.iastate.edu/courses/agron212/Readings/Oat_wheat_history.htm (accessed August 2006).

3. Small E (1999) New crops for Canadian agriculture. In Perspectives on New Crops and New Uses, pp. 15-52 [J Janick, editor]. Alexandria, VA: ASHS Press.

4. North American Millers' Association (2000) Oat foods: a smart choice. http://www.namamillers.org/prd_o.html (accessed August 2006).

5. Andlauer W \& Furst P (2002) Nutraceuticals: a piece of history, present status and outlook. Food Res Int 35, $171-176$.

6. Delaney B, Nicolosi RJ, Wilson TA, Carlson T, Frazer S, Zheng GH, Hess R, Ostergren K, Haworth J \& Knutson N (2003) $\beta$-Glucan fractions from barley and oats are similarly antiatherogenic in hypercholesterolemic Syrian golden hamsters. J Nutr 133, 468-475.

7. Erkkila AT, Herrington DM, Mozaffarian D \& Lichtenstein AH (2005) Cereal fiber and whole-grain intake are associated with reduced progression of coronary-artery atherosclerosis in postmenopausal women with coronary artery disease. Am Heart J 150, 94-101.

8. Ramakers JD, Volman JJ, Onning G, Biorklund M, Mensink RP \& Plat J (2005) Immune stimulating effects of oat $\beta$-glucan on enterocytes in vitro. FASEB J 19, A948.

9. Tsikitis VL, Albina JE \& Reichner JS (2004) $\beta$-Glucan affects leukocyte navigation in a complex chemotactic gradient. Surgery 136, 384-389.

10. Behall KM, Scholfield DJ, Hallfrisch JG \& LiljebergElmstahl HGM (2006) Consumption of both resistant starch and $\beta$-glucan improves postprandial plasma glucose and insulin in women. Diabetes Care 29, 976-981.

11. Braaten JT, Scott FW, Wood PJ, Riedel KD, Wolynetz MS, Brule D \& Collins MW (1994) High $\beta$-glucan oat bran and oat gum reduce postprandial blood-glucose and insulin in 
subjects with and without type-2 diabetes. Diabetic Med 11, 312-318.

12. Naumann E, Van Rees AB, Onning G, Oste R, Wydra M \& Mensink RP (2006) $\beta$-Glucan incorporated into a fruit drink effectively lowers serum LDL-cholesterol concentrations. Am J Clin Nutr 83, 601-605.

13. Lasztity R (1998) Oat grain - a wonderful reservoir of natural nutrients and biologically active substances. Food Rev Int 14, 99-119.

14. Hogberg L, Laurin P, Falth-Magnusson K, et al. (2004) Oats to children with newly diagnosed coeliac disease: a randomised double blind study. Gut 53, 649-654.

15. Chen CY, Milbury PE, Kwak HK, Collins FW, Samuel P \& Blumberg JB (2004) Avenanthramides and phenolic acids from oats are bioavailable and act synergistically with vitamin $\mathrm{C}$ to enhance hamster and human LDL resistance to oxidation. J Nutr 134, 1459-1466.

16. Ozcan MM, Ozkan G \& Topal A (2006) Characteristics of grains and oils of four different oats (Avena sativa L.) cultivars growing in Turkey. Int J Food Sci Nutr 57, $345-352$.

17. Zhou MX, Robards K, Glennie-Holmes M \& Helliwell S (1999) Oat lipids. J Am Oil Chem Soc 76, 159-169.

18. Gudmundsson M \& Eliasson AC (1989) Some physicochemical properties of oat starches extracted from varieties with different oil content. Acta Agric Scand 39, 101-111.

19. Anderson JW (2004) Whole grains and coronary heart disease: the whole kernel of truth. Am J Clin Nutr 80, $1459-1460$

20. Truswell AS (2002) Cereal grains and coronary heart disease. Eur J Clin Nutr 56, 1-14.

21. Martensson O, Biörklund M, Lambo AM, Duenas-Chasco M, Irastorza A, Holst O, Norin E, Welling G, Öste R \& Önning G (2005) Fermented, ropy, oat-based products reduce cholesterol levels and stimulate the bifidobacteria flora in humans. Nutr Res 25, 429-442.

22. Onning G, Wallmark A, Persson M, Akesson B, Elmstahl S \& Oste R (1999) Consumption of oat milk for 5 weeks lowers serum cholesterol and LDL cholesterol in free-living men with moderate hypercholesterolemia. Ann Nutr Metab 43, 301-309.

23. Lovegrove JA, Clohessy A, Milon H \& Williams CM (2000) Modest doses of $\beta$-glucan do not reduce concentrations of potentially atherogenic lipoproteins. Am J Clin Nutr 72, 49-55.

24. Maki KC, Shinnick F, Seeley MA, Veith PE, Quinn LC, Hallissey PJ, Temer A \& Davidson MH (2003) Food products containing free tall oil-based phytosterols and oat $\beta$-glucan lower serum total and LDL cholesterol in hypercholesterolemic adults. J Nutr 133, 808-813.

25. Van Horn L, Liu K, Gerber J, Garside D, Schiffer L, Gernhofer N \& Greenland P (2001) Oats and soy in lipidlowering diets for women with hypercholesterolemia: is there synergy? J Am Diet Assoc 101, 1319-1325.

26. Karmally W, Montez MG, Palmas W, Martinez W, Branstetter A, Ramakrishnan R, Holleran SF, Haffner SM \& Ginsberg HN (2005) Cholesterol-lowering benefits of oat-containing cereal in Hispanic Americans. J Am Diet Assoc 105, 967-970.

27. Berg A, Konig D, Deibert P, Grathwohl D, Berg A, Baumstark MW \& Franz IW (2003) Effect of an oat bran enriched diet on the atherogenic lipid profile in patients with an increased coronary heart disease risk. A controlled randomized lifestyle intervention study. Ann Nutr Metab 47, 306-311.

28. Katz DL, Nawaz H, Boukhalil J, Giannamore V, Chan W, Ahmadi R \& Sarrel PM (2001) Acute effects of oats and vitamin $\mathrm{E}$ on endothelial responses to ingested fat. Am $J$ Prev Med 20, 124-129.

29. Katz DL, Nawaz H, Boukhalil J, Chan W, Ahmadi R, Giannamore V \& Sarrel PM (2001) Effects of oat and wheat cereals on endothelial responses. Prev Med 33, 476-484.

30. Wood PJ, Braaten JT, Scott FW, Riedel KD, Wolynetz MS \& Collins MW (1994) Effect of dose and modification of viscous properties of oat gum on plasma-glucose and insulin following an oral glucose-load. Br J Nutr 72, 731-743.

31. Uusitupa MIJ, Miettinen TA, Sarkkinen ES, Ruuskanen E, Kervinen K \& Kesaniemi YA (1997) Lathosterol and other non-cholesterol sterols during treatment of hypercholesterolaemia with $\beta$-glucan-rich oat bran. Eur J Clin Nutr 51, 607-611.

32. Kerckhoffs D, Brouns F, Hornstra G \& Mensink RP (2002) Effects on the human serum lipoprotein profile of $\beta$-glucan, soy protein and isoflavones, plant sterols and stanols, garlic and tocotrienols. J Nutr 132, 2494-2505.

33. Laitinen J, Uusitupa M, Ruuskanen E, Makinen E, Toskala E, Kervinen K \& Kesaniemi A (1995) A controlled study on the effect of $\beta$-glucan-rich oat bran on serum-lipids in hypercholesterolemic subjects - relation to apolipoprotein-E phenotype. Eur J Clin Nutr 49, S245.

34. Ripsin CM, Keenan JM, Jacobs DR, et al. (1992) Oat products and lipid lowering - a metaanalysis. JAMA 267, 3317-3325.

35. Mackay S \& Ball MJ (1992) Do beans and oat bran add to the effectiveness of a low-fat diet. Eur J Clin Nutr 46, 641-648.

36. Braaten JT, Wood PJ, Scott FW, Wolynetz MS, Lowe MK, Bradley-White P \& Collins MW (1994) Oat $\beta$-glucan reduces blood cholesterol concentration in hypercholesterolemic subjects. Eur J Clin Nutr 48, 465-474.

37. Uusitupa MIJ, Ruuskanen E, Mäkinen E, Laitinen J, Toskala E, Kervinen K \& Kesäniemi YA (1992) A controlled study on the effect of $\beta$-glucan-rich oat bran on serum lipids in hypercholesterolemic subjects - relation to apolipoproteinE phenotype. J Am Coll Nutr 11, 651-659.

38. Behall KM, Scholfield DJ \& Hallfrisch J (1997) Effect of $\beta$-glucan level in oat fiber extracts on blood lipids in men and women. J Am Coll Nutr 16, 46-51.

39. Katz DL, Evans MA, Chan W, Nawaz H, Comerford BP, Hoxley ML, Njike VY \& Sarrel PM (2004) Oats, antioxidants and endothelial function in overweight, dyslipidemic adults. J Am Coll Nutr 23, 397-403.

40. Colleoni-Sirghie M, Fulton DB \& White PJ (2003) Structural features of water soluble $(1,3)(1,4)-\beta$-D-glucans from high- $\beta$-glucan and traditional oat lines. Carbohydr Polym 54, 237-249.

41. Miller SS, Fulcher RG, Sen A \& Arnason JT (1995) Oat endosperm cell-walls. 1. Isolation, composition, and comparison with other tissues. Cereal Chem 72, 421-427.

42. Saastamoinen M, Plaami S \& Kumpulainen J (1992) Genetic and environmental variation in $\beta$-glucan content of oats cultivated or tested in Finland. J Cereal Sci 16, 279-290.

43. Autio K, Myllymaki O, Suortti T, Saastamoinen M \& Poutanen K (1992) Physical-properties of $(1 \rightarrow 3),(1 \rightarrow 4)$ $\beta$-D-glucan preparates isolated from Finnish oat varieties. Food Hydrocoll 5, 513-522.

44. Saastamoinen M, Plaami S \& Kumpulainen J (1992) $\beta$-Glucan and phytic acid content of oats cultivated in Finland. Acta Agric Scand 42, 6-11.

45. Collins FW (2000) Advances in the preparative liquid chromatography of bioactive phytochemicals. J Clin Ligand Assay 23, 273-282. 
46. Parker JE, Hassell GME, Mottram DS \& Guy RCE (2000) Sensory and instrumental analyses of volatiles generated during the extrusion cooking of oat flours. J Agric Food Chem 48, 3497-3506.

47. Martinez-Tome M, Murcia MA, Frega N, Ruggieri S, Jimenez AM, Roses F \& Parras P (2004) Evaluation of antioxidant capacity of cereal brans. J Agric Food Chem 52, 4690-4699.

48. Heinio RL, Oksman-Caldentey KM, Latva-Kala K, Lehtinen P \& Poutanen K (2001) Effect of drying treatment conditions on sensory profile of germinated oat. Cereal Chem 78, 707-714.

49. Zadernowski R, Nowak-Polakowska H \& Rashed AA (1999) The influence of heat treatment on the activity of lipo- and hydrophilic components of oat grain. J Food Process Preserv 23, 177-191.

50. Peterson DM (2001) Oat antioxidants. J Cereal Sci 33, 115-129.

51. Emmons CL, Peterson DM \& Paul GL (1999) Antioxidant capacity of oat (Avena sativa L.) extracts. 2. In vitro antioxidant activity and contents of phenolic and tocol antioxidants. J Agric Food Chem 47, 4894-4898.

52. Emmons CL \& Peterson DM (1999) Antioxidant activity and phenolic contents of oat groats and hulls. Cereal Chem 76, 902-906.

53. Prior RL, Wu XL \& Schaich K (2005) Standardized methods for the determination of antioxidant capacity and phenolics in foods and dietary supplements. J Agric Food Chem 53, 4290-4302.

54. Huang DJ, Ou BX \& Prior RL (2005) The chemistry behind antioxidant capacity assays. J Agric Food Chem 53, 1841-1856.

55. Zielinski H \& Kozlowska H (2000) Antioxidant activity and total phenolics in selected cereal grains and their different morphological fractions. J Agric Food Chem 48, 2008-2016.

56. Auerbach RH \& Gray DA (1999) Oat antioxidant extraction and measurement - towards a commercial process. $J$ Sci Food Agric 79, 385-389.

57. Perez-Jimenez J \& Saura-Calixto F (2005) Literature data may underestimate the actual antioxidant capacity of cereals. J Agric Food Chem 53, 5036-5040.

58. Lehtinen P \& Laakso S (2000) Inhibition of linoleic acid oxidation by interaction with a protein-rich oat fraction. J Agric Food Chem 48, 5654-5657.

59. Czerwinski J, Bartnikowska E, Leontowicz H, Lange E, Leontowicz M, Katrich E, Trakhtenberg S \& Gorinstein S (2004) Oat (Avena sativa L.) and amaranth (Amaranthus hypochondriacus) meals positively affect plasma lipid profile in rats fed cholesterol-containing diets. J Nutr Biochem 15, 622-629.

60. Gray DA, Clarke MJ, Baux C, Bunting JP \& Salter AM (2002) Antioxidant activity of oat extracts added to human LDL particles and in free radical trapping assays. $J$ Cereal Sci 36, 209-218.

61. Peterson DM, Emmons CL \& Hibbs AH (2001) Phenolic antioxidants and antioxidant activity in pearling fractions of oat groats. J Cereal Sci 33, 97-103.

62. Handelman GJ, Cao G, Walter MF, Nightingale ZD, Paul GL, Prior RL \& Blumberg JB (1999) Antioxidant capacity of oat (Avena sativa L.) extracts. 1. Inhibition of lowdensity lipoprotein oxidation and oxygen radical absorbance capacity. J Agric Food Chem 47, 4888-4893.

63. Panfili G, Fratianni A \& Irano M (2004) Improved normalphase high-performance liquid chromatography procedure for the determination of carotenoids in cereals. J Agric Food Chem 52, 6373-6377.
64. Peterson DM, Jensen CM, Hoffman DL \& MannerstedtFogelfors B (2007) Oat tocols: saponification vs. direct extraction and analysis in high-oil genotypes. Cereal Chem 84, 56-60.

65. Panfili G, Fratianni A \& Irano M (2003) Normal phase highperformance liquid chromatography method for the determination of tocopherols and tocotrienols in cereals. J Agric Food Chem 51, 3940-3944.

66. Podda M, Weber C, Traber MG \& Packer L (1996) Simultaneous determination of tissue tocopherols, tocotrienols, ubiquinols, and ubiquinones. J Lipid Res 37, 893-901.

67. Balz MK, Schulte E \& Their HP (1993) Simultaneous determination of $\alpha$-tocopheryl acetate, tocopherols and tocotrienols by HPLC with fluorescence detection in foods. Fett Wiss Technol 95, 215-220.

68. Kramer JKG, Blais L, Fouchard RC, Melnyk RA \& Kallury KMR (1997) A rapid method for the determination of vitamin $\mathrm{E}$ forms in tissues and diet by high-performance liquid chromatography using a normal-phase diol column. Lipids 32, 323-330.

69. Abidi SL \& Mounts TL (1997) Reversed-phase highperformance liquid chromatographic separations of tocopherols. J Chromatogr A 782, 25-32.

70. Richheimer SL, Kent MC \& Bernart MW (1994) Reversedphase high-performance liquid-chromatographic method using a pentafluorophenyl bonded phase for analysis of tocopherols. J Chromatogr A 677, 75-80.

71. Redaelli R, Pisacane V \& Berardo N (2004) Antioxidants in Italian oat cultivars. Agro Food Industry Hi-Tech 15, 38-40.

72. Kamal-Eldin A, Gorgen S, Pettersson J \& Lampi AM (2000) Normal-phase high-performance liquid chromatography of tocopherols and tocotrienols - comparison of different chromatographic columns. J Chromatogr A $\mathbf{8 8 1}$, 217-227.

73. Peterson DM (1995) Oat tocols - concentration and stability in oat products and distribution within the kernel. Cereal Chem 72, 21-24.

74. Peterson DM \& Qureshi AA (1993) Genotype and environment effects on tocols of barley and oats. Cereal Chem 70, 157-162.

75. Hampshire $\mathbf{J}$ (2003) Investigations of vitamin $\mathbf{E}$ contents in oat varieties and industrial milling oats. Deut Lebensm Rundsch 99, 222-231.

76. Piironen V, Syvaoja EL, Varo P, Salminen K \& Koivistoinen P (1986) Tocopherols and tocotrienols in cereal products from Finland. Cereal Chem 63, 78-81.

77. Bryngelsson S, Mannerstedt-Fogelfors B, Kamal-Eldin A, Andersson R \& Dimberg LH (2002) Lipids and antioxidants in groats and hulls of Swedish oats (Avena sativa L). J Sci Food Agric 82, 606-614.

78. Peterson DM \& Wood DF (1997) Composition and structure of high-oil oat. J Cereal Sci 26, 121-128.

79. White DA, Fisk ID \& Gray DA (2006) Characterisation of oat (Avena sativa L.) oil bodies and intrinsically associated E-vitamers. J Cereal Sci 43, 244-249.

80. Moreau RA, Powell MJ \& Singh V (2003) Pressurized liquid extraction of polar and nonpolar lipids in corn and oats with hexane, methylene chloride, isopropanol, and ethanol. J Am Oil Chem Soc 80, 1063-1067.

81. Qureshi AA, Mo HB, Packer L \& Peterson DM (2000) Isolation and identification of novel tocotrienols from rice bran with hypocholesterolemic, antioxidant, and antitumor properties. J Agric Food Chem 48, 3130-3140.

82. Balandrin MF, Kinghorn AD \& Farnsworth NR (1993) Plant-derived natural-products in drug discovery and development - an overview. ACS Symp Ser 534, 2-12. 
83. Hart DJ \& Scott KJ (1995) Development and evaluation of an HPLC method for the analysis of carotenoids in foods, and the measurement of the carotenoid content of vegetables and fruits commonly consumed in the UK. Food Chem 54, 101-111.

84. Graf E \& Eaton JW (1990) Antioxidant functions of phytic acid. Free Radic Biol Med 8, 61-69.

85. Larsson M \& Sandberg AS (1992) Phytate reduction in oats during malting. J Food Sci 57, 994-997.

86. Lolas GM, Palamidis N \& Markakis P (1976) Phytic acid total phosphorus relationship in barley, oats, soybeans, and wheat. Cereal Chem 53, 867-871.

87. Miller GA, Youngs VL \& Oplinger ES (1980) Environmental and cultivar effects on oat phytic acid concentration. Cereal Chem 57, 189-191.

88. Miller GA, Youngs VL \& Oplinger ES (1980) Effect of available soil-phosphorus and environment on the phytic acid concentration in oats. Cereal Chem 57, 192-194.

89. Hurrell RF (2002) Enhanced iron absorption from cereal and legume grains by phytic acid degradation. ACS Symp Ser 816, 117-129.

90. Chen C, Milbury P, Kwak H, O'Leary J, Collins F \& Blumberg J (2002) Antioxidant capacity and bioavailability of oat polyphenolics. Gerontologist 42, 9.

91. Kocheva LS, Borisenkov MF, Karmanov AP, Mishurov VP, Spirikhin LV \& Monakov YB (2005) Structure and antioxidant characteristics of wheat and oat lignins. Russ $J$ Appl Chem 78, 1343-1350.

92. Jac P, Polasek M \& Pospisilova M (2006) Recent trends in the determination of polyphenols by electromigration methods. J Pharm Biomed Anal 40, 805-814.

93. Naczk M \& Shahidi F (2004) Extraction and analysis of phenolics in food. J Chromatogr A 1054, 95-111.

94. Mazza G, Cacace JE \& Kay CD (2004) Methods of analysis for anthocyanins in plants and biological fluids. J AOAC Int 87, 129-145.

95. Robards K (2003) Strategies for the determination of bioactive phenols in plants, fruit and vegetables. J Chromatogr A 1000, 657-691.

96. Robbins RJ (2003) Phenolic acids in foods: an overview of analytical methodology. J Agric Food Chem 51, 2866-2887.

97. Gioacchini AM, Roda A, Galletti GC, Bocchini P, Manetta AC \& Baraldini M (1996) High-performance liquid chromatographic-electrospray mass spectrometric analysis of phenolic acids and aldehydes. J Chromatogr A 730, 31-37.

98. Careri M, Bianchi F \& Corradini C (2002) Recent advances in the application of mass spectrometry in food-related analysis. J Chromatogr A 970, 3-64.

99. Guth H \& Grosch W (1994) Quantitative-analysis of caffeic and ferulic acids in oatmeal - comparison of a conventional method with a stable-isotope dilution assay. Z LebensmUnters Forsch 199, 195-197.

100. Emmons CL \& Peterson DM (2001) Antioxidant activity and phenolic content of oat as affected by cultivar and location. Crop Sci 41, 1676-1681.

101. Adom KK \& Liu RH (2002) Antioxidant activity of grains. J Agric Food Chem 50, 6182-6187.

102. Phillipson JD (2003) 50 Years of medicinal plant research every progress in methodology is a progress in science. Planta Med 69, 491-495.

103. Mattila P, Pihlava JM \& Hellstrom J (2005) Contents of phenolic acids, alkyl- and alkenylresorcinols, and avenanthramides in commercial grain products. J Agric Food Chem 53, 8290-8295.
104. Weidner S \& Paprocka J (1996) Phenolic acids and dormancy in oat (Avena sativa $\mathrm{L}$ ) and rye (Secale cereale $\mathrm{L}$ ) caryopses. Acta Physiol Plant 18, 277-286.

105. Xing YM \& White PJ (1997) Identification and function of antioxidants from oat groats and hulls. J Am Oil Chem Soc 74, 303-307.

106. Weidner S, Paprocka J \& Lukaszewicz D (1996) Changes in free, esterified and glycosidic phenolic acids in cereal grains during the after-ripening. Seed Sci Technol 24, 107-114.

107. Krygier K, Sosulski F \& Hogge L (1982) Free, esterified, and insoluble-bound phenolic-acids. 1. Extraction and purification procedure. J Agric Food Chem 30, 330-334.

108. Sosulski F, Krygier K \& Hogge L (1982) Free, esterified, and insoluble-bound phenolic-acids 3. Composition of phenolic-acids in cereal and potato flours. J Agric Food Chem 30, 337-340.

109. Faulds CB \& Williamson G (1999) The role of hydroxycinnamates in the plant cell wall. J Sci Food Agric 79, 393-395.

110. Andlauer W \& Furst P (1998) Antioxidative power of phytochemicals with special reference to cereals. Cereal Foods World 43, 356-360.

111. Duve KJ \& White PJ (1991) Extraction and identification of antioxidants in oats. J Am Oil Chem Soc 68, 365-370.

112 Iiyama K, Lam TBT \& Stone BA (1990) Phenolic-acid bridges between polysaccharides and lignin in wheat internodes. Phytochemistry 29, 733-737.

113. Renger A \& Steinhart H (2000) Ferulic acid dehydrodimers as structural elements in cereal dietary fibre. Eur Food Res Technol 211, 422-428.

114. Lam TBT, Kadoya K \& Iiyama K (2001) Bonding of hydroxycinnamic acids to lignin: ferulic and $p$-coumaric acids are predominantly linked at the benzyl position of lignin, not the $\beta$-position, in grass cell walls. Phytochemistry 57, 987-992.

115. Grabber JH, Ralph J \& Hatfield RD (2002) Model studies of ferulate-coniferyl alcohol cross-product formation in primary maize walls: implications for lignification in grasses. J Agric Food Chem 50, 6008-6016.

116. Grabber JH, Ralph J \& Hatfield RD (2000) Cross-linking of maize walls by ferulate dimerization and incorporation into lignin. J Agric Food Chem 48, 6106-6113.

117. Yu PQ, Maenz DD, Mckinnon JJ, Racz VJ \& Christensen DA (2002) Release of ferulic acid from oat hulls by aspergillus ferulic acid esterase and trichoderma xylanase. J Agric Food Chem 50, 1625-1630.

118. Grabber JH, Ralph J \& Hatfield RD (1998) Ferulate crosslinks limit the enzymatic degradation of synthetically lignified primary walls of maize. J Agric Food Chem 46, 2609-2614.

119. Russell WR, Burkitt MJ, Provan GJ \& Chesson A (1999) Structure-specific functionality of plant cell wall hydroxycinnamates. J Sci Food Agric 79, 408-410.

120. Bily AC, Burt AJ, Ramputh AL, Livesey J, Regnault-Roger C \& Philogène BR (2004) HPLC-PAD-APCI/MS assay of phenylpropanoids in cereals. Phytochem Anal 15, 9-15.

121. Bunzel M, Ralph J, Marita JM, Hatfield RD \& Steinhart H (2001) Diferulates as structural components in soluble and insoluble cereal dietary fibre. J Sci Food Agric 81, 653-660.

122. Kern SM, Bennett RN, Needs PW, Mellon FA, Kroon PA \& Garcia-Conesa MT (2003) Characterization of metabolites of hydroxycinnamates in the in vitro model of human small intestinal epithelium Caco-2 cells. J Agric Food Chem 51, 7884-7891.

123. Ralph J, Quideau S, Grabber JH \& Hatfield RD (1994) Identification and synthesis of new ferulic acid dehydrodi- 
mers present in grass cell-walls. J Chem Soc Perkin Trans 1, 3485-3498.

124. Brett CT, Wende G, Smith AC \& Waldron KW (1999) Biosynthesis of cell-wall ferulate and diferulates. J Sci Food Agric 79, 421-424.

125. Schatz PF, Ralph J, Lu FC, Guzei IA \& Bunzel M (2006) Synthesis and identification of 2,5-bis-(4-hydroxy-3-methoxyphenyl)-tetrahydrofuran-3,4-dicarboxylic acid, an unanticipated ferulate 8-8-coupling product acylating cereal plant cell walls. Org Biomolec Chem 4, 2801-2806.

126. Yu P, Mckinnon JJ \& Christensen DA (2005) Hydroxycinnamic acids and ferulic acid esterase in relation to biodegradation of complex plant cell walls. Can J Anim Sci 85, 255-267.

127. Hatfield RD, Ralph J \& Grabber JH (1999) Cell wall crosslinking by ferulates and diferulates in grasses. J Sci Food Agric 79, 403-407.

128. Okazaki Y, Isobe T, Iwata Y, et al. (2004) Metabolism of avenanthramide phytoalexins in oats. Plant J 39, 560-572.

129. Jastrebova J, Skoglund M, Nilsson J \& Dimberg LH (2006) Selective and sensitive LC-MS determination of avenanthramides in oats. Chromatographia 63, 419-423.

130. Peterson DM, Hahn MJ \& Emmons CL (2002) Oat avenanthramides exhibit antioxidant activities in vitro. Food Chem 79, 473-478.

131. Ishihara A, Ohtsu Y \& Iwamura H (1999) Biosynthesis of oat avenanthramide phytoalexins. Phytochemistry 50, $237-242$.

132. Nie L, Wise ML, Peterson DP \& Meydani M (2004) Avenanthramides, polyphenols from oats, modulate smooth muscle cell (SMC) proliferation and nitric oxide (NO) production. Free Radic Biol Med 37, S40.

133. Molteberg EL, Solheim R, Dimberg LH \& Frolich W (1996) Variation in oat groats due to variety, storage and heat treatment. 2. Sensory quality. J Cereal Sci 24, 273-282.

134. Dimberg LH, Molteberg EL, Solheim R \& Frolich W (1996) Variation in oat groats due to variety, storage and heat treatment. 1. Phenolic compounds. J Cereal Sci 24, 263-272.

135. Bratt K, Sunnerheim K, Bryngelsson S, Fagerlund A, Engman L, Andersson RE \& Dimberg LH (2003) Avenanthramides in oats (Avena sativa L.) and structureantioxidant activity relationships. J Agric Food Chem 51, 594-600.

136. Ji LL, Lay D, Chung E, Fu Y \& Peterson DM (2003) Effects of avenanthramides on oxidant generation and antioxidant enzyme activity in exercised rats. Nutr Res 23, 1579-1590.

137. Liu LP, Zubik L, Collins FW, Marko M \& Meydani M (2004) The antiatherogenic potential of oat phenolic compounds. Atherosclerosis 175, 39-49.

138. Webb AL \& Mccullough ML (2005) Dietary lignans: potential role in cancer prevention. Nutr Canc 51, 117-131.

139. Lampe JW, Atkinson C \& Hullar MAJ (2006) Assessing exposure to lignans and their metabolites in humans. JAOAC Int 89, 1174-1181.

140. Smeds AI, Eklund PC, Sjoholm RE, Willfor SM, Nishibe S, Deyama T \& Holmbom BR (2007) Quantification of a broad spectrum of lignans in cereals, oilseeds, and nuts. J Agric Food Chem 55, 1337-1346.

141. Adlercreutz H \& Mazur W (1997) Phyto-oestrogens and western diseases. Ann Med 29, 95-120.

142. Johnsen NF, Hausner H, Olsen A, Tetens I, Christensen J, Knudsen KE, Overvad K \& Tjønneland A (2004) Intake of whole grains and vegetables determines the plasma enterolactone concentration of Danish women. J Nutr 134, 2691-2697.
143. Mazur W (1998) Phytoestrogen content in foods. Baillieres Clin Endocrinol Metab 12, 729-742.

144. Lampe JW (2003) Isoflavonoid and lignan phytoestrogens as dietary biomarkers. $J$ Nutr 133, 956S-964S.

145. Adlercreutz H (2002) Phyto-oestrogens and cancer. Lancet Oncol 3, 364-373.

146. Raffaelli B, Hoikkala A, Leppala E \& Wahala K (2002) Enterolignans. J Chromatogr B 777, 29-43.

147. Kitts DD, Yuan YV, Wijewickreme AN \& Thompson LU (1999) Antioxidant activity of the flaxseed lignan secoisolariciresinol diglycoside and its mammalian lignan metabolites enterodiol and enterolactone. Mol Cell Biochem 202, 91-100.

148. Piironen V, Lindsay DG, Miettinen TA, Toivo J \& Lampi AM (2000) Plant sterols: biosynthesis, biological function and their importance to human nutrition. J Sci Food Agric 80, 939-966.

149. Piironen V, Toivo J \& Lampi AM (2002) Plant sterols in cereals and cereal products. Cereal Chem 79, 148-154.

150. Eichenberger W \& Urban B (1984) Sterols in seeds and leaves of oats (Avena-sativa L). Plant Cell Rep 3, 226-229.

151. Knights BA (1968) Comparison of grain sterol fractions of cultivated and wild oat species. Phytochemistry 7, 2067-2068.

152. Knights BA (1967) Identification of plant sterols using combined GLC/mass spectrometry. J Gas Chromatogr 5, 273-282.

153. Knights BA \& Laurie W (1967) Application of combined gas-liquid chromatography-mass spectrometry to identification of sterols in oat seed. Phytochemistry 6, 407-416.

154. Määttä K, Lampi A-M, Petterson J, Fogelfors BM, Piironen V \& Kamal-Eldin A (1999) Phytosterol content in seven oat cultivars grown at three locations in Sweden. J Sci Food Agric 79, 1021-1027.

155. Dutta PC \& Appelqvist LA (1996) Saturated sterols (stanols) in unhydrogenated and hydrogenated edible vegetable oils and in cereal lipids. J Sci Food Agric 71, 383-391.

156. Hakala P, Lampi AM, Ollilainen V, Werner U, Murkovic M, Wahala K, Karkola S \& Piironen P (2002) Steryl phenolic acid esters in cereals and their milling fractions. J Agric Food Chem 50, 5300-5307.

157. Osbourn AE (2003) Saponins in cereals. Phytochemistry 62, $1-4$.

158. Oleszek WA (2002) Chromatographic determination of plant saponins. J Chromatogr A 967, 147-162.

159. Oleszek W \& Bialy Z (2006) Chromatographic determination of plant saponins - an update (2002-2005). J Chromatogr A 1112, 78-91.

160. Onning G, Asp NG \& Sivik B (1993) Saponin content in different oat varieties and in different fractions of oat grain. Food Chem 48, 251-254.

161. Onning G \& Asp NG (1993) Analysis of saponins in oat kernels. Food Chem 48, 301-305.

162. Sparg SG, Light ME \& Van Staden J (2004) Biological activities and distribution of plant saponins. J Ethnopharmacol 94, 219-243.

163. Gylling H \& Miettinen TA (2005) The effect of plant stanoland sterol-enriched foods on lipid metabolism, serum lipids and coronary heart disease. Ann Clin Biochem 42, 254-263.

164. Kritchevsky D \& Chen SC (2005) Phytosterols - health benefits and potential concerns: a review. Nutr Res 25, $413-428$.

165. Marinangeli CPF, Varady KA \& Jones PJH (2006) Plant sterols combined with exercise for the treatment of hypercholesterolemia: overview of independent and synergistic mechanisms of action. J Nutr Biochem 17, 217-224. 
166. Moreau RA, Whitaker BD \& Hicks KB (2002) Phytosterols, phytostanols, and their conjugates in foods: structural diversity, quantitative analysis, and health-promoting uses. Prog Lipid Res 41, 457-500.

167. Moruisi KG, Oosthuizen W \& Opperman AM (2006) Phytosterols/stanols lower cholesterol concentrations in familial hypercholesterolemic subjects: a systematic review with meta-analysis. J Am Coll Nutr 25, 41-48.

168. Patel MD \& Thompson PD (2006) Phytosterols and vascular disease. Atherosclerosis 186, 12-19.

169. Rao AV \& Koratkar R (1997) Anticarcinogenic effects of saponins and phytosterols. In ACS Symposium Series, vol. 662, pp. 313-324 [F Shahidi, editor]. New York: Oxford University Press.

170. Lasztity R, Hidevegi M \& Bata A (1998) Saponins in food. Food Rev Int 14, 371-390.

171. Shi J, Arunasalam K, Yeung D, Kakuda Y, Mittal G \& Jiang YM (2004) Saponins from edible legumes: chemistry, processing, and health benefits. J Med Food 7, 67-78.

172. Onning G, Wang Q, Westrom BR, Asp NG \& Karlsson SW (1996) Influence of oat saponins on intestinal permeability in vitro and in vivo in the rat. Br J Nutr 76, 141-151.

173. Onning G \& Asp NG (1995) Effect of oat saponins and different types of dietary fibre on the digestion of carbohydrates. Br J Nutr 74, 229-237.

174. Onning G \& Asp NG (1995) Effect of oat saponins on plasma and liver lipids in gerbils (Meriones unguiculatus) and rats. Br J Nutr 73, 275-286.

175. Onning G, Juillerat MA, Fay L \& Asp NG (1994) Degradation of oat saponins during heat processing - effect of $\mathrm{pH}$, stainless-steel, and iron at different temperatures. J Agric Food Chem 42, 2578-2582.

176. Asp NG, Mattsson B \& Onning G (1992) Variation in dietary fiber, $\beta$-glucan, starch, protein, fat and hull content of oats grown in Sweden 1987-1989. Eur J Clin Nutr 46, $31-37$.

177. Theuwissen E \& Mensink RP (2007) Simultaneous intake of $\beta$-glucan and plant stanol esters affects lipid metabolism in slightly hypercholesterolemic subjects. J Nutr 137, 583-588.

178. Berghofer E, Grzeskowiak B, Mundigler N, Sentall WB \& Walcak J (1998) Antioxidative properties of faba bean-, soybean- and oat tempeh. Int J Food Sci Nutr 49, 45-54.

179. Yu L, Perret J, Davy B, Wilson J \& Melby CL (2002) Antioxidant properties of cereal products. J Food Sci 67, 2600-2603.

180. Bryngelsson S, Dimberg LH \& Kamal-Eldin A (2002) Effects of commercial processing on levels of antioxidants in oats (Avena sativa L.). J Agric Food Chem 50, 1890-1896.

181. Bryngelsson S, Ishihara A \& Dimberg LH (2003) Levels of avenanthramides and activity of hydroxycinnamoyl-CoA: hydroxyanthranilate $n$-hydroxycinnamoyl transferase (HHT) in steeped or germinated oat samples. Cereal Chem 80, 356-360.

182. Dimberg LH, Sunnerheim K, Sundberg B \& Walsh K (2001) Stability of oat avenanthramides. Cereal Chem 78, $278-281$. 